\title{
Recombinant human bone morphogenetic protein- 2 in the treatment of bone fractures
}

\author{
Neil Ghodadra \\ Kern Singh
}

Department of Orthopedic Surgery, Rush University Medical Center, Chicago, Illinois, USA
Correspondence: Kern Singh

Department of Orthopaedic Surgery,

Rush University Medical Center, 1725

West Harrison Street, POB I063,

Chicago, Illinois 60612, USA

$\mathrm{Tel}+\mathrm{I} 3124322373$

Fax +13129421516

Email kern.singh@rushortho.com

\begin{abstract}
Over one million fractures occur per year in the US and are associated with impaired healing increasing patient morbidity, stress, and economic costs. Despite improvements in surgical technique, internal fixation, and understanding of biologics, fracture healing is delayed or impaired in up to $4 \%$ of all fractures. Complications due to impaired fracture healing present therapeutic challenges to the orthopedic surgeon and often lead to chronic functional and psychological disability for the patient. As a result, it has become clinically desirable to augment mechanical fixation with biologic strategies in order to accelerate osteogenesis and promote successful arthrodesis. The discovery of bone morphogenic protein (BMP) has been pivotal in understanding the biology of fracture healing and has been a source of intense clinical research as an adjunct to fracture treatment. Multiple in vitro and in vivo studies in animals have elucidated the complex biologic interactions between BMPs and cellular receptors and have convincingly demonstrated rhBMP-2 to be a safe, effective treatment option to enhance bone healing. Multiple clinical trials in trauma surgery have provided level 1 evidence for the use of rhBMP-2 as a safe and effective treatment of fractures. Human clinical trials have provided further insight into BMP-2 dosage, time course, carriers, and efficacy in fracture healing of tibial defects. These promising results have provided hope that a new biologic field of technology has emerged as a useful adjunct in the treatment of skeletal injuries and conditions.
\end{abstract}

Keywords: bone morphogenic protein-2, bone fracture, bone healing

\section{Introduction}

The devastating effects of fractures are felt every year in the US. Over one million fractures occur per year and are associated with impaired healing increasing patient morbidity, stress, and economic cost (Einhorn 1995, 1998). Despite improvements in surgical technique, internal fixation and understanding of biologics, fracture healing is delayed or impaired in up to 4\% of all fractures (Whittle et al 1992; Tornetta et al 1994; Einhorn 1995; Heckman and Sarasohn-Kahn 1997; Marsh 1998; Karladani et al 2000; Young and Rayan 2000). Factors affecting fracture healing include severity of injury, patient comorbidities, and surgical fixation. Complications due to impaired fracture healing present therapeutic challenges to the orthopedic surgeon and often lead to chronic functional and psychological disability for the patient. As a result, it has become clinically desirable to augment mechanical fixation with biologic strategies in order to accelerate osteogenesis and promote successful arthrodesis. The purposes of the following manuscript include: 1) to review the biology of bone morphogenic protein-2 (BMP-2, Medtronic Sofamor Danek, Memphis, TN, USA); 2) to identify important animal data that support the use of BMP-2 in fracture treatment; 3) to present recently published human clinical data on the use of BMP-2 in orthopedic fracture care.

\section{Fracture repair}

Bone is a unique organ that continuously remodels and has the capability to regenerate throughout adult life (Cheng et al 2003). Fracture repair includes a complex interaction 
between mechanical (fracture stability) and biological factors (growth factors/proteins). The physiological and biological factors responsible for the regeneration of bone are coupled to and dependent on BMPs.

Fracture of bone leads to a cascade of events including activation of the complement cascade and an inflammatory response associated with vascular injury leading to cell extravasation and signaling (Gautschi et al 2007). Activated macrophages release growth factors that stimulate endothelial cells to express plasminogen activator and procollagenase (Schmitt et al 1999). Initiation of the clotting cascade by platelets allows the localized collection of blood to clot and form a hematoma. This hemostatic plug prevents further blood loss and provides a medium for the activity of various growth factors including platelet-derived growth factor (PDGF), transforming growth factor-beta (TGF- $\beta$ ), and beta-fibroblast growth factor ( $\beta$-FGF) (Hollinger and Wong 1996).

Approximately 3 days after a fracture, a repair blastema forms consisting of new blood vessels, macrophages, and collagen (Hollinger and Wong 1996). Growth factors selectively bind to collagen, forming a substrate to optimize interaction between TGF- $\beta$, $\beta$-FGF, PDGF, BMPs, and receptor cells (Figure 1). Osteoprogenitor cells localized to the periosteum and endosteum of fractured bone attach to granulation tissue and differentiate into chondrocytes and osteoblasts via cell signaling. The aggregate effects of cellular transduction and enhanced cellular-growth factor interaction help to regenerate bone via osteoblastic and osteoclastic activity and ensure fracture healing by 6-8 weeks after injury (Hollinger and Wong 1996). Degradation products

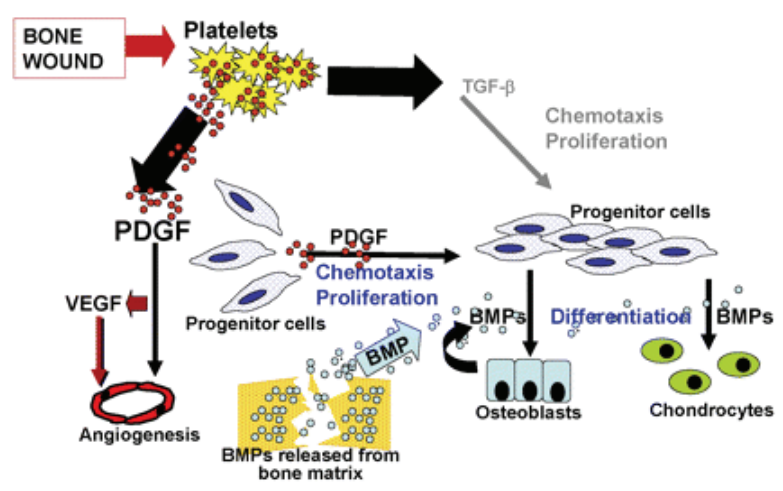

Figure I Cell signaling in chemotaxis and cell proliferation during wound-healing: Platelet derived growth factor (PDGF), vascular endothelial growth factor (VEGF), and transforming growth factor-beta (TGF- $\beta$ ) play an integral role in the signal cascade responsible for chemotaxis and cell migration during wound-healing.The recruitment of osteoprogenitor cells and their proliferation provides a pool of cells that will respond to bone morphogenic protein (BMP). Reproduced with permission from Hollinger JO, et al 2008. Recombinant human platelet-derived growth factor: biology and clinical applications.J Bone Joint Surg Am, 90:48-54. Copyright (C) 2008. The Journal of Bone and Joint Surgery, Inc. from the extracellular matrix stimulate the differentiation of macrophages into osteoclasts in order to provide additional cells for continued fracture healing (Schmitt et al 1999).

The final pathway in bone healing and regeneration depends on the interaction between BMP's/growth factors with the various cell lines at the site of injury (Reddi 1994). Sufficient quantities of biologically active BMPs and competent cells interact to regenerate bone (Schmitt et al 1999).

\section{BMP biology}

In 1965, Marshall R Urist discovered a substance in the extracellular bone matrix that had the ability to induce osteogenesis when implanted into extraskeletal tissue (Urist 1965). Ever since this seminal discovery of bone morphogenic proteins, the role of BMP has expanded from basic biology to clinical applications. In 1998, scientists at the Genetics Institute in Cambridge, MA, USA derived the amino acid sequence of BMPs. This discovery led to the expression of complementary DNAs and recognization of BMP in the family of the transforming growth factor- $\beta$ supergene family (Einhorn 1998). Over the past 2 decades, 20 BMPs with varying abilities to induce cartilage or bone formation have been identified by investigators (Gautschi et al 2007). The structure of 16 different human BMPs have been identified and designated as BMP-1 to BMP-16. With the exception of BMP-1, the BMPs are a subgroup of the transforming growth factor- $\beta$ superfamily which is a group of differentiation factors that have been shown to play an integral role in tissue repair (Ozkaynak et al 1992; Barnes et al 1999, 2003; Termaat et al 2005).

Enhanced fracture healing relies on two processes: mechanical and biologic intervention (Linkhart et al 1996; Claes et al 1998; Bostrom et al 1999). Biological agents recapitulate the process of both embryological bone formation and fracture healing; thus these agents have the potential to be used clinically in their natural setting (Marsh 1998). Among the numerous cytokines and growth factors such as BMPs, TGF- $\beta$, FGF-1 (fibroblast growth factor), and IGF-1 (insulin like growth factor) involved in fracture healing, BMPs are regarded as the key regulators in the cascade of events required for skeletal repair (Onishi et al 1998; Sakou 1998; Wozney and Rosen 1998).

In the first 5 days after a fracture, a cascade of events integral to fracture healing occurs. Progenitor cells indigenous to the fracture site are recruited through cell signaling via BMPs. The interaction of BMP-2 with these osteoprogenitor cells leads to induction of bone-forming osteoblasts. This marks a sentinel event for bone regeneration. BMPs bind 
and initiate a cell signal through a transmembrane receptor complex formed by type I and II serine/threonine kinase receptor proteins. Type II receptors are active continuously and function upstream of the type I receptors but cannot independently initiate cell signaling (Wrana et al 1994). After binding BMP-2, the type II receptor kinase phosphorylates the type I receptor, generating an intracellular response.

Studies have shown that BMP-2 through 7 and BMP-9 have the unique ability to induce differentiation of mesenchymal stem cells into osteoblasts (Chen et al 1991; Yamaguchi et al 1991; Hughes et al 1995; Mayer et al 1996). BMP-2, 6, and 9 play an important role in the early phase of differentiation of mesenchymal progenitor cells to preosteoblasts. In mesenchymal progenitor and osteoblastic cells, Cheng et al demonstrated the relative osteoconductivity of different BMPs at various stages in the differentiation process. Specifically, BMP-2, 6, and 9 were shown to play a pivotal role in the early phase of the differentiation of mesenchymal progenitor cells to pre-osteoblasts. These findings could implicate BMP-2, 6, and 9 as essential effectors in fracture healing where there is an abundance of pluripotent cells and pre-osteoblasts.

Although many BMP subtypes have been shown to have osteoinductive properties, only rhBMP-2 and rhBMP-7 have been developed and used for clinical applications (Cheng et al 2003). Multiple animal models have demonstrated that fracture healing can be accelerated by local administration of rhBMP-2 (Ozkaynak et al 1992; Bostrom et al 1999; den Boer et al 2002). BMP-2 plays an important role in the early phase of differentiation of mesenchymal progenitor cells to pre-osteoblasts.

Tsuji et al (2006) evaluated the role of BMP-2 in fracture healing by creating transgenic mice lacking limb specific expression of BMP-2. These mice did not have defects in skeletal patterns but did develop dose-dependent defects in bone mineral density. Femoral fractures in these mice showed failure to heal by day 20 compared with heterozygotes and control groups. Mice lacking BMP-2 had delayed activation of the periosteum in response to the fracture in addition to the absence of callus formation and mesenchymal progenitor cells.

\section{In vitro BMP-2 analysis}

The functions of BMPs have been evaluated in many cell lines including osteoprogenitor cells, osteoblasts, and chondroblasts. In a study using $\mathrm{C} 3 \mathrm{H} 10 \mathrm{~T} 1 / 2$ cells (mouse mesodermal progenitor cells), Wang et al (1993) demonstrated that high concentrations of BMP-2 induced differentiation into chondrocytes and bone cells. Other studies have implicated BMP-2 in the conversion of rat calvaria derived multipotent cells (ROB-C26) and clonal myoblast cells ( $\mathrm{C} 2 \mathrm{C} 12)$ into cells of the osteoblast phenotype (Yamaguchi et al 1991; Katagiri et al 1994). Kanatani et al (1995) showed that BMP-2 stimulated bone resorption through direct stimulation of osteoclast formation and activation of mature osteoclasts in stromal cells of mouse bone cell cultures. Cheng et al (2003) used osteoblastic progenitor cell lines to demonstrate that BMP-2 was able to induce both early and late osteogenic markers and matrix mineralization. These studies provide compelling evidence for the role of BMP-2 in the biology of bone regeneration, leading to further interest and study in animal models.

\section{Lower order animal trials}

In several preclinical studies, a single percutaneous injection of recombinant human BMP-2 (rhBMP-2) in a calcium phosphate paste (alpha bone substitute material $[\alpha-B S M]$ accelerated osteotomy site healing in rabbit ulnar, canine tibial, and primate fibular osteotomy models (Finkemeier 2002; Khan et al 2005). In a study by Seeherman et al (2006a), a single percutaneous administration of $1.5 \mathrm{mg} / \mathrm{mL}$ rh BMP-2/calcium phosphate matrix increased primate fibular osteotomy site callus area and accelerated radiographic evidence of healing up to 2 weeks after injury (Figure 2). In this study, a 1-week delay in rhBMP-2 treatment led to accelerated healing through direct bone formation. The authors noted that treatment with rhBMP-2 led to an increase in the number of Cbfa-1 positive cells in the osteotomy site. Cbfa-1 is a transcription factor that works with Osterix (OSX) to regulate osteoblast specific genes required for osteoblast differentiation and bone formation. These findings correlate with in vitro studies that demonstrate that rhBMP-2 upregulates expression of both Cbfa-1 and OSX (Wozney and Rosen 1998; Kawaguchi et al 2001; Kolbeck et al 2003). On the basis of these results, Seeherman et al (2006a) concluded that an injectable form of rhBMP-2/-BSM can potentially be administered at any time up to 2 weeks after fracture injury accelerating the healing of closed fractures in humans.

Bouxsein et al (2001) studied the effect of rhBMP-2 in fracture healing in a rabbit ulnar osteotomy model. Seventytwo rabbits had mid-ulnar osteotomies and were divided into 3 treatment groups: 1) rhBMP-2/absorbable collagen sponge (ACS), 2) absorbable collagen sponge, 3) placebo. The retention of rhBMP-2 at the osteotomy site was determined with imaging of ${ }^{125}$ I-labeled rhBMP-2. The data revealed that osteotomy sites treated with rhBMP-2 healed 33\% faster than the other two groups. At each time point analyzed (3, 4, 6 weeks), 

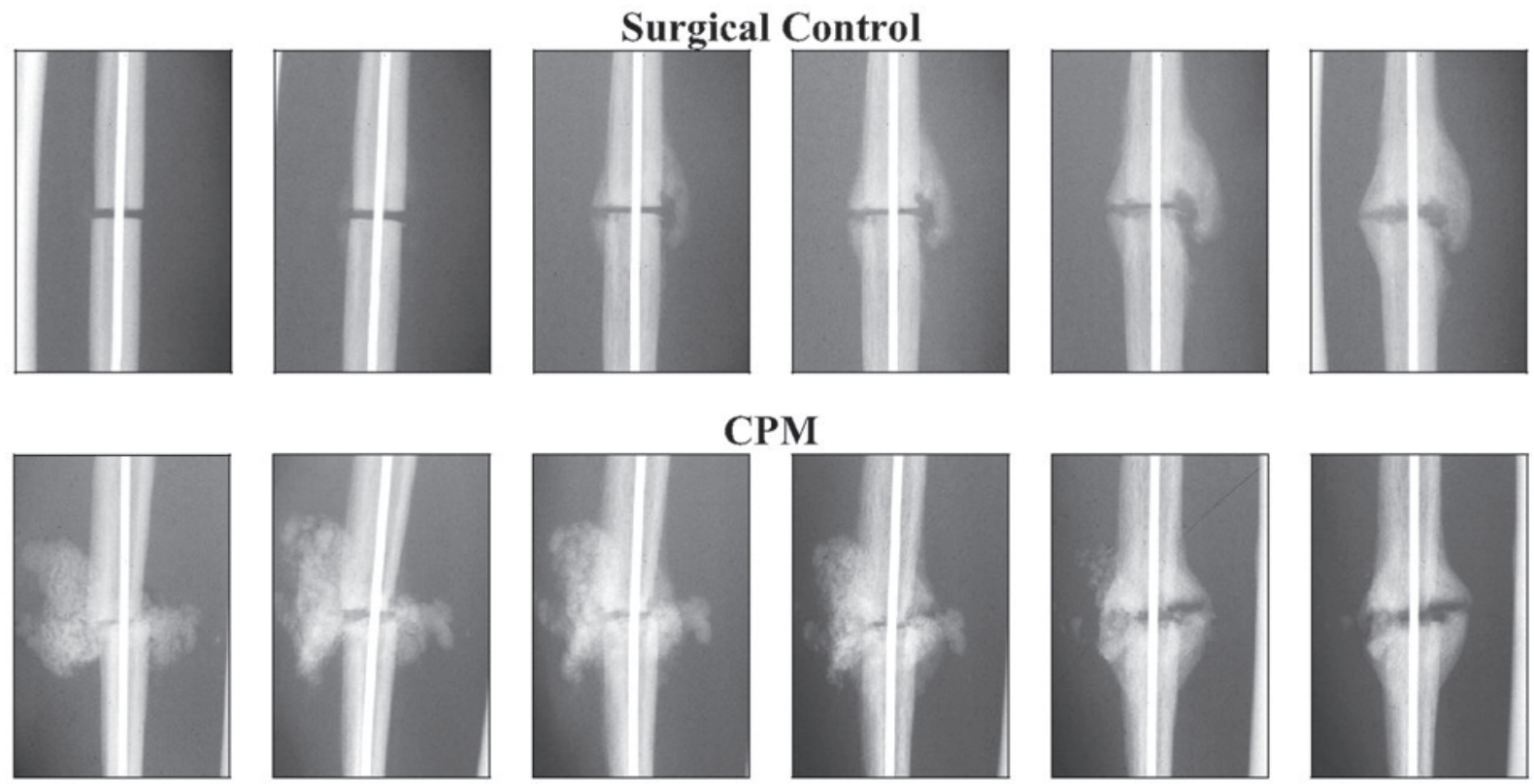

\section{CPM}
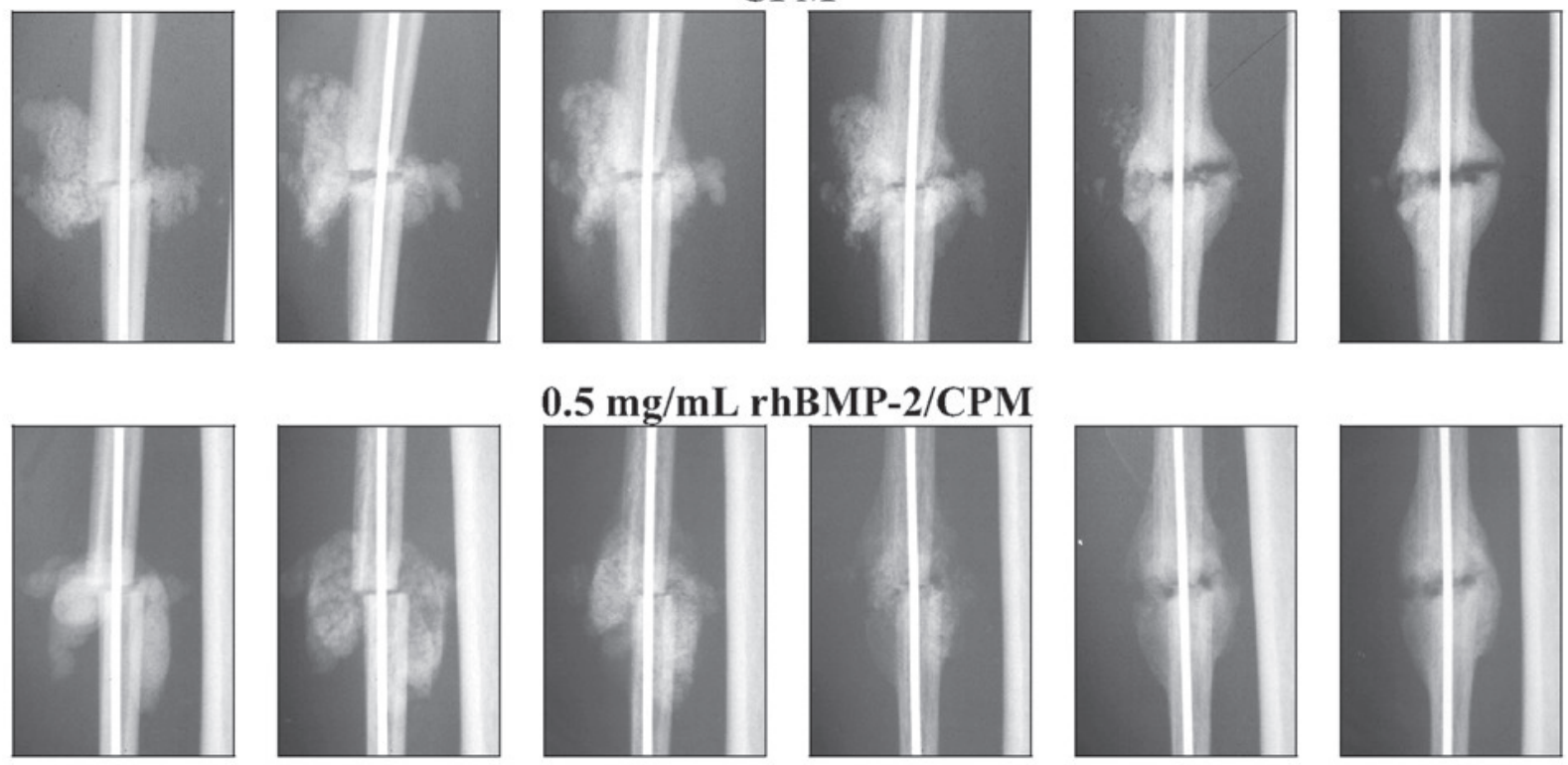

\section{$0.5 \mathrm{mg} / \mathrm{mL}$ rhBMP-2/CPM}
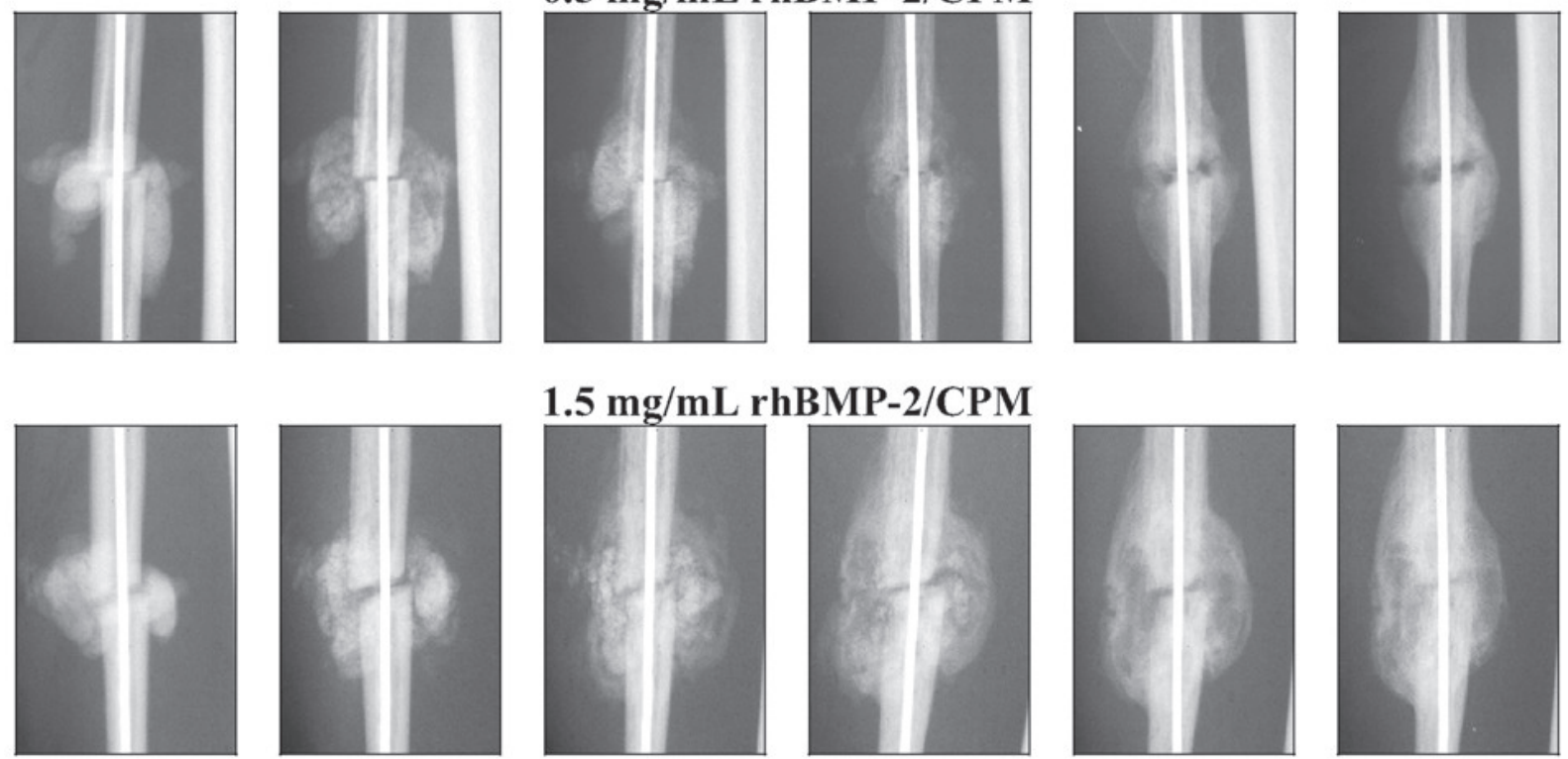

\section{$1.5 \mathrm{mg} / \mathrm{mL}$ rhBMP-2/CPM}
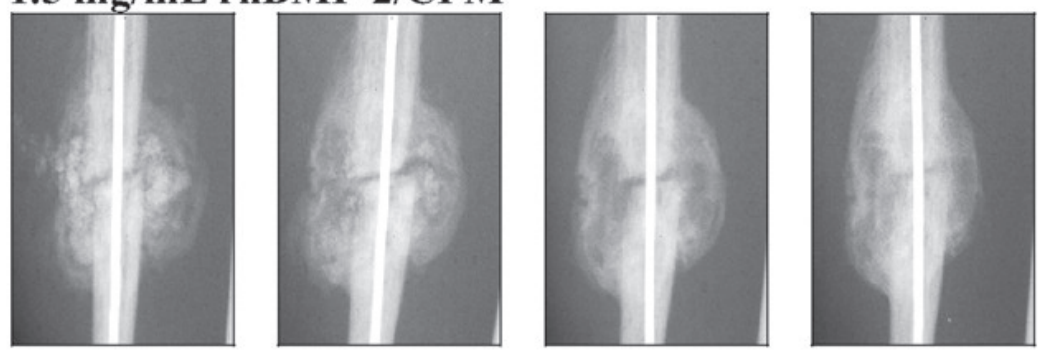

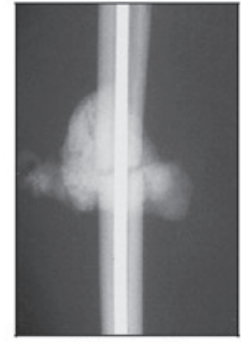

1 Week

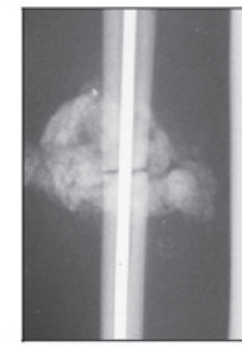

2 Weeks

\section{$4.5 \mathrm{mg} / \mathrm{mL}$ rhBMP-2/CPM}

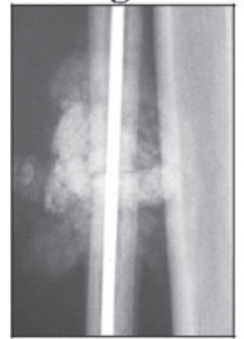

3 Weeks

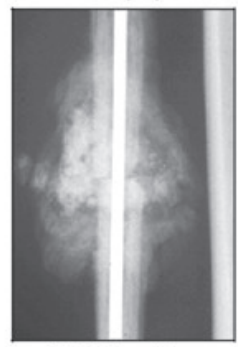

4 Weeks

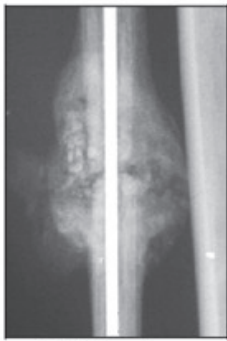

6 Weeks

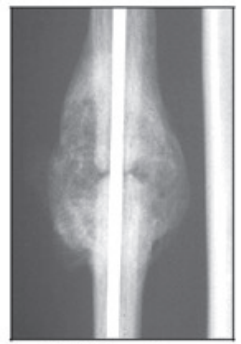

8 Weeks

Figure 2 Postoperative radiographic appearance of the nonhuman primate fibular osteotomy sites that were untreated, treated with calcium phosphate matrix (CPM), and treated with $0.5,1.5$, and $4.5 \mathrm{mg} / \mathrm{mL}$ rhBMP-2/CPM administered I week after surgery. Reproduced with permission from Seeherman H, et al 2006a. rhBMP-2/calcium phosphate matrix accelerates osteotomy-site healing in a nonhuman primate model at multiple treatment times and concentrations.J Bone Joint Surg Am, 88: $144-60$. Copyright @ 2006. The Journal of Bone and Joint Surgery, Inc. 
enhanced healing in the rhBMP-2 treated group appeared to be more rapid with greater callus formation and advanced callus maturation. The authors concluded that the presence of larger and more mature callus in the rhBMP-2 treatment group was consistent with the increased biomechanical properties of the ulna treated with rhBMP-2.

Other animal studies have also shown enhanced fracture healing following rhBMP-2 treatment. Welch et al (1998), in a tibial fracture model in goats, found that limbs treated with rhBMP-2/ACS had increased callus formation, radiographic healing parameters, and torsional stiffness at 3 and 6 weeks post-treatment. Dynamic histomorphometric analysis revealed increased callus formation consistent with recruitment of osteoprogenitor cells (Boden et al 1998). Luppen et al (2002) studied 49 rabbits that were injected with saline or prednisone prior to creating bilateral ulnar osteotomies. One osteotomy was treated with rhBMP-2/ACS, and the contralateral osteotomy served as a control (Luppen et al 2002). Healing was assessed in these animals with computed tomography, torsional biomechanics, and histology. Although prednisolone inhibited healing in the control group, rhBMP-2/ACS enhanced fracture healing in both prednisolone- and saline-treated groups.

In a rat femur fracture model, Lee et al (2002) created a $2 \mathrm{~cm}$ defect that was filled with rhBMP-2/ACS allograft. The authors reported $75 \%$ new bone incorporation into allograft at 4 weeks and $100 \%$ at 8 weeks. Einhorn et al (2003) used a femur fracture model in 144 rats to determine the effects of a single percutaneous injection of rhBMP-2 on fracture healing. The three treatment groups included a control group, a buffer vehicle group, and a rhBMP-2/buffer group. Torsional biomechanical testing indicated that the stiffness of the rhBMP-2 treated group was twice that of the two other control groups at the 2-, 3-, and 4-week time points. At 4 weeks, the strength of the rhBMP-2 treated fractures was $77 \%$ greater than that of the other groups. By 4 weeks, remodeling of the hard callus and recorticalization were observed in the rhBMP-2 treated fracture sites, whereas cartilage and/or soft tissue were still present in the control fracture sites.

Several studies have looked at the effects of rhBMP-2 on fracture healing in canine fracture models. In a study of mid-diaphyseal femoral defects filled with rhBMP2-allograft in 21 dogs, Zabka et al (2001) noted more balanced allograft resorption and bone formation in the rhBMP-2 group compared with the cancellous bone group and ACS groups. Pluhar et al (2001) studied augmentation of allograft with rhBMP$2 / \mathrm{ACS}$ in a canine intercalary femoral defect. The authors found that rhBMP-2/ACS allograft had results equal to or greater than those of autogenous graft. RhBMP-2 graft also resulted in greater callus formation. In a study of $18 \mathrm{dogs}$ with bilateral ulnar defects, Cook et al (2005) compared allograft augmentation with rhBMP-2 against BMP-7. RhBMP-2 treated defects formed greater bone at early time periods, with this trend continuing throughout the study. At the 12-week interval, bridging bone formed in all rhBMP-2 treated and autograft treated groups compared with 4 of 6 BMP-7 treated defects. Mean torsional strength was measured at $78 \%$ of an intact ulna, whereas autograft showed $47 \%$ strength and BMP-7 showed 38\% strength.

Although several studies have reported enhanced fracture healing in animals with rhBMP-2 delivered in a buffer, optimal bone formation requires a carrier (Blokhuis et al 2001; Bouxein et al 2001; Seeherman 2001; Einhorn et al 2003). Carriers optimize BMP concentration at the pivotal stages of fracture healing, allowing osteoprogenitor cells to migrate to the site of repair, proliferate and differentiate into osteoclasts and osteoblasts. Moreover, carriers provide an osteoconductive matrix allowing for better handling properties needed for injection or implantation (Seeherman 2001). Bone regeneration can be optimized in segmental defects through the use of BMP carriers providing compression resistance and appropriate elution (Seeherman 2001).

A variety of BMP-carrier combinations has been used in animal models to enhance bone formation in segmental defects (den Boer et al 2003). A potential problem with most BMP-carrier combinations is that a second open surgical procedure is necessary for delayed administration of BMP after initial surgery to augment the repair. Additionally, soft tissue injury may prevent adequate initial treatment and require another open procedure for BMP implantation. An injectable BMP-carrier combination may allow physicians to circumvent this potential limitation. Multiple animal studies have reported accelerated fracture healing with the use of rhBMP-2 in an injectable calcium phosphate cement carrier (Li et al 2003; Edwards et al 2004; Seeherman et al 2006b; Swiontkowski et al 2006). Currently, clinical trials are evaluating the efficacy of rhBMP-2-carrier combination in the treatment of closed fractures.

Using a novel adenoviral gene therapy technique, Lieberman et al (1999) used BMP-2 producing bone marrow cells to treat rats with femoral defects. The results of this group were compared with a group treated with rhBMP-2 and 3 control groups including defects treated with demineralized bone matrix, $\beta$-galactosidase transduced bone marrow cells, and untreated defects. At the 2-month time point, 22 of 24 defects in the gene therapy group and all defects in 
the rhBMP-2 group showed enhanced fracture healing. In contrast, 1 of 32 defects in the three control groups healed. Thus, Lieberman et al (1999) showed that gene therapy can potentially be used as a therapeutic delivery system for rhBMP-2 in a feasible, efficacious manner. With a similar technique, Lieberman et al noted enhanced bone healing in hindlimbs of mice treated with helper-dependent adenoviral vector producing BMP-2 (Abe et al 2002).

Despite the potential use of viral vectors to express growth factors, questions remain regarding its potential for uncontrolled BMP synthesis and possible malignant cell induction. Multiple studies have questioned the impact of excess BMP-2 production in patients with osteosarcoma. With high doses of BMP, there will be more bone formation and rapid osteoinduction than desired (Valentin-Opran et al 2002). BMP-2 and BMP-2 receptors are expressed in a variety normal and malignant cell types, including osteosarcoma. Guo et al (1999) reported expression of BMP-2 receptor mRNA was correlated with metastasis of osteosarcoma. However, no data have shown that BMPs induce malignant transformation of cells. Although some studies have suggested that BMP-2 may stimulate the proliferation of malignant cells (Kleeff et al 1999; Langenfeld et al 2003), most studies have shown that BMP-2 inhibits or has no effect on the proliferation of malignant cells (Soda et al 1998; Orui et al 2000; Kumagai et al 2006). With these conflicting reports, rhBMP-2 should not be implanted at the site of resected tumor or in patients with active malignancy.

\section{Clinical trials}

Multiple clinical trials in trauma surgery have provided level 1 evidence for the use of rhBMP-2 as a safe and effective treatment of fractures. In a prospective randomized, controlled study, Jones et al (2004a, b) studied the efficacy of rhBMP-2 (INFUSE bone graft; Medtronic Sofamor Danek, Memphis, TN, USA) on an absorbable collagen sponge combined with freeze-dried cancellous autograft for grafting of diaphyseal tibial defects. Thirty patients were randomly enrolled in one of two groups: 1) control group with autogenous iliac crest bone graft, 2) treatment group with cancellous allograft with rhBMP-2/ACS. Patients were followed for 12 months with treatment failures defined as the inability to heal by 12-month follow-up or the need for secondary intervention to induce fracture healing. Five patients in the control group were deemed treatment failures whereas 2 of 15 patients in the rhBMP-2 group did not obtain a solid arthrodesis. Jones et al (2004a, b) concluded that rhBMP-2 with cancellous allograft had a similar rate of healing to that of autogenous bone graft without donor site complaints, with reduced blood loss, and with shortened surgery time.

In a landmark multicenter study by the BESTT study group (BMP-2 Evaluation in Surgery for Tibial Trauma), Govender et al (2002) reported the results of a prospective, randomized controlled, single-blind study to evaluate the safety and efficacy of the use of rhBMP-2 to accelerate healing and decrease the need for secondary intervention in open tibial fractures. The 450 patients evaluated in this study were randomized to one of three groups: 1) intramedullary nail fixation and soft tissue management, 2) IM nail fixation, soft tissue management, and $0.75 \mathrm{mg} / \mathrm{mL}$ (6 mg) rhBMP-2/ACS implant, 3) IM nail fixation, soft tissue management, and $0.75 \mathrm{mg} / \mathrm{mL}$ (6 mg) rhBMP2/ACS implant and $1.5 \mathrm{mg} / \mathrm{mL}$ (12 mg) of rhBMP-2/ACS. At the time of definitive wound closure, the rhBMP-2 was placed over the fracture. The severity of the open wound was graded according to the Gustilo-Anderson classification and was used to stratify the randomization. Stratum A comprised Gustilo Anderson types I, II, IIIA whereas Stratum B comprised Gustilo-Anderson type IIIB open fractures.

Four-hundred and twenty-one (91\%) of the patients were seen at 12-month followup. At every time point (10 weeks to 12-month follow-up), the rhBMP-2 treated groups had a significantly greater percentage of patients who had successful healing without hardware failure or the need for secondary intervention to achieve union (Figure 3). Compared with the control group, patients treated with $1.5 \mathrm{mg} / \mathrm{mL}$ rhBMP-2 had a $44 \%$ reduction in the risk of failure $(p=0.0005)$,

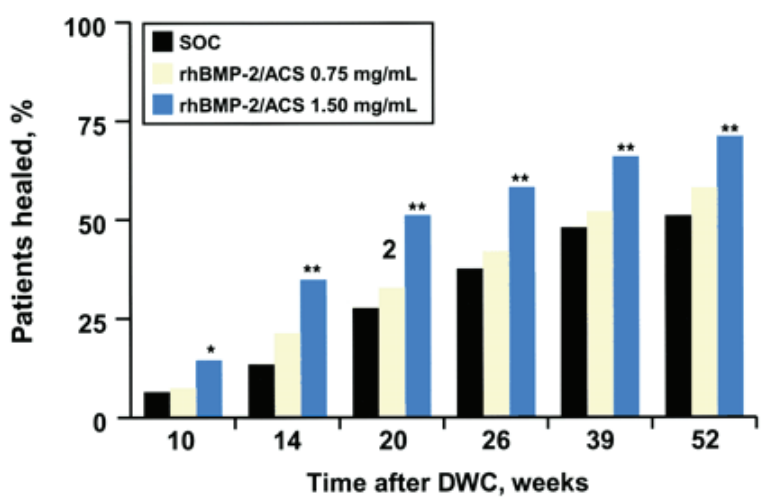

Figure 3 Rate of fracture healing. Determination of fracture-healing was based on treating surgeons' clinical and radiographic assessment. SOC = standard of care control group with IM nail fixation and soft-tissue management, rhBMP-2/ACS = groups treated with recombinant human bone morphogenic protein-2 in an absorbable collagen sponge implant, and DWC = definitive wound closure. The Fisher exact test pairwise comparison of the control group and the $1.50 \mathrm{mg} / \mathrm{mL} \mathrm{rhBMP-2/ACS}$ group revealed a p-value of $0.048 \mathrm{I}$ at 10 weeks, $<0.000 \mathrm{I}$ at 14 weeks, $0.000 \mathrm{I}$ at 20 weeks, 0.0025 at 39 weeks, and 0.0009 at 52 weeks. $*=p<0.05$; $* *=p<0.01$. Reproduced with permission from Govender S, et al 2002. Recombinant human bone morphogenetic protein-2 for treatment of open tibial fractures: a prospective, controlled, randomized study of four hundred and fifty patients.J Bone Joint Surg Am, 84-A:2 I 23-34. Copyright (C) 2002. The Journal of Bone and Joint Surgery, Inc. 
significantly fewer invasive interventions $(p=0.0264)$ such as bone-grafting and nail exchange, and significantly faster fracture healing $(p=0.0022)$. Moreover, significantly more patients treated with $1.5 \mathrm{mg} / \mathrm{mL}$ rhBMP-2 had healing at the fracture site at postoperative visits from 10 weeks to 12 months $(\mathrm{p}=0.008)$. At 6 months, the healing rate observed in the $1.5 \mathrm{mg} / \mathrm{mL}$ rhBMP-2 group was $21 \%$ higher than that in the control group. Compared with control patients, those treated with $1.5 \mathrm{mg} / \mathrm{mL}$ of rhBMP-2 also had significantly fewer hardware failures $(\mathrm{p}=0.0174)$, fewer infections (in association with Gustilo-Anderson type III injuries; $\mathrm{p}=0.0219)$, and faster wound-healing ( $83 \%$ compared with $65 \%$ had wound healing at 6 weeks; $p=0.001)$.

The results of this study demonstrate that patients with Gustilo type IIIA or IIIB fracture who had been treated with $1.5 \mathrm{mg} / \mathrm{mL}$ rhBMP-2 implant had a significantly reduced rate of infection compared with the control. The authors speculated that this effect was likely due to earlier achievement of fracture stability. The authors also noticed accelerated soft tissue healing and reduction in pain in patients treated with rhBMP-2. This potential reduction in pain may be related to an increased vascular supply that has been observed experimentally in rhBMP-2 induced bone formation. The authors also noted that infection rates were higher in this study compared to other reports as their definition of infection was conservative and included both superficial and deep wounds. The data from this study led to the EMEA (European Agency for the Evaluation of Medicinal Products) approval of rhBMP-2/ACS in 2002 and FDA approval in 2004 for open tibial fractures treated with an IM nail (McKay et al 2007). An economic model based on the results of the BESTT study trial revealed cost savings to the payer when rhBMP-2 was reserved for patients with Gustilo type IIIA or IIIB fractures (Jones et al 2004b).

Between 1996 and 1999, two concurrent prospective, randomized controlled multicenter trials were performed to evaluate the efficacy of rhBMP-2 in the treatment of open tibial fractures. Along with the BESTT trial which was subsequently published, a second unpublished study was conducted with the same study design and protocol for 60 patients at 10 level-1 trauma centers in the US (Swiontkowski et al 2006). Since many surgeons were unaware of this smaller study which showed that the rate of secondary intervention was reduced with the addition of rhBMP-2 to reamed or unreamed IM nailing, Swiontkowski et al (2006) reported a subgroup analysis of the combined results of these two studies. With a total of 520 patients from 59 trauma centers, Swiontowski et al analyzed two subgroups: 1) 131 patients with a Gustilo-Anderson type IIIA or IIIB open tibial fractures, 2) 113 patients treated with reamed intramedullary nailing. The first subgroup demonstrated significant improvements with treatment of $1.5 \mathrm{mg} / \mathrm{mL}$ rhBMP-2 with fewer bone grafting procedures $(\mathrm{p}=0.0005)$, decreased need for secondary invasive intervention $(\mathrm{p}=0.0065)$, and a lower rate of infection ( $\mathrm{p}=0.0234)$ compared with the control group (Table 1). Analysis of subgroup II revealed that fractures treated with reamed IM nailing had no significant difference between the control and rhBMP-2 groups (Table 2) In this study, Swiontowksi et al (2006) noted that patients in the rhBMP-2 group were bearing weight an average of 32 days sooner than the controls. The authors of this study concluded that rhBMP-2 can be used safely and acutely in patients who present with open tibial fractures with a plan that includes IM nailing and no staged bone-grafting.

Between 2000 and 2003, Jones et al (2006) performed a multicenter randomized controlled trial in 30 patients to investigate the benefit of rhBMP-2 with allograft compared to autogenous bone graft for reconstruction of diaphyseal tibial fractures with cortical defects. Patients included in this study had residual fracture defect consistent with clinical recommendation for staged reconstruction with bone grafting (ie, a cortical defect measuring $1-5 \mathrm{~cm}$ in length and involving at least $50 \%$ of the circumference of the diaphysis) (Watson et al 1995; Whittle et al 1995; Templeman et al 1998); and had to have had initial treatment with either intramedullary nail or external fixation. All 30 patients were enrolled 6-12 weeks after initial injury. Patients allocated to the allograft group received $1.5 \mathrm{mg} / \mathrm{mL}$ rhBMP-2/ACS as an onlay graft. Clinical evaluation of fracture healing included pain assessment with full weight bearing and fracture-site tenderness. The Short Musculoskeletal Function Assessment (SMFA) was administered before and after treatment with radiographs used to document union, the presence of bridging callus, and incorporation of bone-graft material.

Ten patients in the autograft group (66\%) and 13 patients (86\%) in the rhBMP-2/allograft group had healing without further intervention. The mean estimated blood loss was 67\% lower in the rhBMP-2 group (mean 117 $\mathrm{mL})$ than the autograft group (mean 353) $(\mathrm{p}=0.0073)$. There was comparable improvement in SMFA scores between the two groups. No patient developed antibodies to BMP-2 in the rhBMP-2/allograft group. Thus, Jones et al (2006) demonstrated that administration of the rhBMP-2/ACS combined with cancellous allograft for the treatment of diaphyseal tibial fractures with cortical defects was comparable with the overall clinical results achieved for patients who received autogenous bone 
grafting. By eliminating autogenous bone graft harvesting, a rhBMP-2/allograft implant can provide significant clinical benefit with decreased intraoperative blood loss and elimination of morbidity associated with autogenous bone graft harvesting. The authors concluded that rhBMP-2/ allograft is a clinically beneficial and safe alternative to autogenous bone grafting in cases of tibial fractures with extensive tibial diaphyseal bone loss.

Table I Comparison of patient outcomes in the control group and rhBMP-2 treatment group for the Gustilo-Anderson Type-III open fracture subgroup

\begin{tabular}{|c|c|c|c|c|}
\hline Outcome criteria & Control group $(n=65)$ & rhBMP-2 group $(n=66)$ & P value ${ }^{*}$ & $\begin{array}{l}\text { Risk reduction }(95 \% \\
\text { confidence intervals) }\end{array}$ \\
\hline $\begin{array}{l}\text { No. }(\%) \text { of patients receiving } \\
\text { bone graft }\end{array}$ & $13(20)$ & I (2) & 0.0005 & $90 \%(41 \%$ to $98 \%)$ \\
\hline $\begin{array}{l}\text { No. (\%) of patients receiving } \\
\text { invasive secondary procedure }\end{array}$ & $18(28)$ & $6(9)$ & 0.0065 & $68 \%$ (24\% to $86 \%)$ \\
\hline $\begin{array}{l}\text { Time to achievement of full } \\
\text { weight-bearing } \text { (days) }^{-}\end{array}$ & $|26 \pm 6|$ & $95 \pm 38$ & NA & NA \\
\hline $\begin{array}{l}\text { No. (\%) of patients who had } \\
\text { infection }\end{array}$ & $26(40)$ & $13(2 \mid)$ & 0.0234 & $48 \%$ ( $8 \%$ to $70 \%)$ \\
\hline $\begin{array}{l}\text { No. (\%) of patients who had } \\
\text { dynamization }\end{array}$ & $14(22)$ & $14(2 \mid)$ & 1.0000 & $5 \%(-84 \%$ to $50 \%)$ \\
\hline $\begin{array}{l}\text { No. (\%) of patients who had } \\
\text { dynamization subsequent to } \\
\text { screw breakage }\end{array}$ & $16(25)$ & $7(I I)$ & 0.0407 & $56 \%(1 \%$ to $80 \%)$ \\
\hline $\begin{array}{l}\text { Total no. (\%) of patients who } \\
\text { had dynamization }\end{array}$ & $30(46)$ & $21(32)$ & 0.1085 & $30 \%(-8 \%$ to $55 \%)$ \\
\hline
\end{tabular}

Reproduced with permission from Swiontkowski MF, et al 2006. Recombinant human bone morphogenetic protein-2 in open tibial fractures.A subgroup analysis of data combined from two prospective randomized studies.J Bone Joint Surg Am, 88: 1258-65. Copyright @ 2006. The Journal of Bone and Joint Surgery, Inc.

"Fisher exact test (two-tailed value).

${ }^{\dagger}$ Relative risk reduction calculation $=(1-$ rate in rhBMP-2 group/rate in control group $) \times 100$, as described by Bhandari et al.

\#Invasive secondary procedures were defined as one or more of the following: bone-grafting to treat delayed union or nonunion, fibular osteotomy, and/or exchange nailing

$\S$ The values are given as the mean and the standard deviation. NA = not available.

Table 2 Comparison of patient outcomes in control group and rhBMP-2 treatment group for the renamed nailing subgroup

\begin{tabular}{|c|c|c|c|c|}
\hline Outcome criteria & Control group $(n=48)$ & rhBMP-2 group $(n=65)$ & P value* & $\begin{array}{l}\text { Risk reduction }(95 \% \\
\text { confidence intervals) }\end{array}$ \\
\hline $\begin{array}{l}\text { No. (\%) of patients receiving } \\
\text { bone graft }\end{array}$ & $3(6)$ & I (2) & 0.3100 & $67 \%(-201 \%$ to $96 \%)$ \\
\hline $\begin{array}{l}\text { No. (\%) of patients receiving } \\
\text { invasive secondary procedure }\end{array}$ & $7(15)$ & $5(8)$ & 0.3549 & $47 \%$ (-64\% to $83 \%)$ \\
\hline $\begin{array}{l}\text { Time to achievement of full } \\
\text { weight-bearing } \$ \text { (days) }\end{array}$ & $84 \pm 43$ & $80 \pm 37$ & NA & NA \\
\hline $\begin{array}{l}\text { No. (\%) of patients who had } \\
\text { infection }\end{array}$ & $13(27)$ & $12(18)$ & 0.3597 & $30 \%(-43 \%$ to $65 \%)$ \\
\hline $\begin{array}{l}\text { No. }(\%) \text { of patients who had } \\
\text { dynamization }\end{array}$ & $10(2 \mathrm{I})$ & II (I7) & 0.6311 & $19 \%(-77 \%$ to $63 \%)$ \\
\hline $\begin{array}{l}\text { No. (\%) of patients who had } \\
\text { dynamization subsequent to } \\
\text { screw breakage }\end{array}$ & $2(4)$ & $3(5)$ & 1.0000 & $-25 \%(-594 \%$ to $77 \%)$ \\
\hline $\begin{array}{l}\text { Total no. (\%) of patients who } \\
\text { had dynamization }\end{array}$ & $12(25)$ & $14(22)$ & 0.8251 & $12 \%(-74 \%$ to $55 \%)$ \\
\hline
\end{tabular}

Reproduced with permission from Swiontkowski MF, et al 2006. Recombinant human bone morphogenetic protein-2 in open tibial fractures.A subgroup analysis of data combined from two prospective randomized studies.J Bone Joint Surg Am, 88: I258-65. Copyright ( 2006. The Journal of Bone and Joint Surgery, Inc.

"Fisher exact test (two-tailed value).

${ }^{\dagger}$ Relative risk reduction calculation $=(1-$ rate in rhBMP-2 group/rate in control group $) \times 100$, as described by Bhandari et al.

*Invasive secondary procedures were defined as one or more of the following: bone-grafting to treat delayed union or nonunion, fibular osteotomy, and/or exchange nailing. ${ }^{\S}$ The values are given as the mean and the standard deviation. NA = not available. 


\section{Cost analysis}

In a cost analysis study of the use of BMP-2 in open tibial fractures, Garrison et al estimated that the incremental cost per quality adjusted life-year (QALY) gained was greater than US\$50,000 (Garrison et al 2007). There was a $35 \%$ probability that cost per QALY gained was less than US $\$ 50,000$. They concluded that the cost-effectiveness ratio is sensitive to the price of BMP and the severity of open tibial fractures. Jones et al (2004b) conducted an economic analysis to evaluate the cost of adding rhBMP-2 to the cost of initial fracture repair. In a comparison of treating an open tibial fracture with a nail versus a nail with rhBMP-2, they found that $10.5 \%$ of the rhBMP- 2 cost would be offset by reductions in secondary interventions and infections. They estimated that the use of rhBMP-2 with intramedullary nailing would result in cost savings of US\$3,570 per patient.

\section{Conclusion}

Marshall Urist's discovery of BMP has been pivotal in understanding the biology of fracture healing and has been a source of intense clinical research as an adjunct to fracture treatment. Multiple in vitro and in vivo studies in animals have elucidated the complex biologic interactions between BMPs and cellular receptors and have convincingly demonstrated rhBMP-2 to be a safe, effective treatment option to enhance bone healing. Human clinical trials have provided further insight into BMP-2 dosage, time course, carriers, and efficacy in fracture healing. Several human clinical trials have convincingly demonstrated the positive effects of BMP-2 on fracture healing in tibial defects. These promising results have provided hope that a new biologic field of technology has emerged as a useful adjunct in the treatment of skeletal injuries and conditions. Further research and clinical studies are necessary to delineate the molecular mechanisms underlying bone formation and fracture healing.

\section{Disclosures}

No financial or material support was provided for this study, and neither author has any conflict of interest to disclose.

\section{References}

Abe N, et al. 2002. Enhancement of bone repair with a helper-dependent adenoviral transfer of bone morphogenetic protein-2. Biochem Biophys Res Commun, 297:523-7.

Barnes GL, et al. 1999.Growth factor regulation of fracture repair. J Bone Miner Res, 14:1805-15.

Barnes GL, et al. 2003. Osteoblast-related transcription factors Runx2 (Cbfa1/AML3) and MSX2 mediate the expression of bone sialoprotein in human metastatic breast cancer cells. Cancer Res, 63:2631-7.
Bhandari M, Guyatt GH, Swiontkowski MF. 2001. User's guide to the orthopaedic literature: how to use an article about a surgical therapy. J Bone Joint Surg Am, 83:916-26.

Blokhuis TJ, et al. 2001. Biomechanical and histological aspects of fracture healing, stimulated with osteogenic protein-1. Biomaterials, $22: 725-30$

Boden SD. et al. 1998. Laparoscopic anterior spinal arthrodesis with rhBMP-2 in a titanium interbody threaded cage. J Spinal Disord, 11:95-101.

Bostrom MP, et al. 1999. Osteoinductive growth factors in preclinical fracture and long bone defects models. Orthop Clin North Am, 30:647-58.

Bouxsein ML, et al. 2001. Recombinant human bone morphogenetic protein2 accelerates healing in a rabbit ulnar osteotomy model. $J$ Bone Joint Surg Am, 83-A:1219-30.

Chen TL, et al. 1991. Bone morphogenetic protein-2b stimulation of growth and osteogenic phenotypes in rat osteoblast-like cells: comparison with TGF-beta 1. J Bone Miner Res, 6:1387-93.

Cheng H, et al. 2003. Osteogenic activity of the fourteen types of human bone morphogenetic proteins (BMPs). J Bone Joint Surg Am, 85-A:1544-52.

Claes LE, et al. 1998 Effects of mechanical factors on the fracture healing process. Clin Orthop Relat Res, 355(Suppl):S132-47.

Cook SD, et al. 2005. Bone defect healing with an osteogenic protein-1 device combined with carboxymethylcellulose. J Biomed Mater Res B Appl Biomater, 75:137-45.

den Boer FC, et al. 2003. Healing of segmental bone defects with granular porous hydroxyapatite augmented with recombinant human osteogenic protein-1 or autologous bone marrow. J Orthop Res, 21:521-8.

den Boer FC, et al. 2002. Effect of recombinant human osteogenic protein-1 on the healing of a freshly closed diaphyseal fracture. Bone, 31:158-64.

Edwards RB 3rd, et al. 2004. Percutaneous injection of recombinant human bone morphogenetic protein-2 in a calcium phosphate paste accelerates healing of a canine tibial osteotomy. J Bone Joint Surg Am, 86-A:1425-38.

Einhorn TA, et al. 2003. A single percutaneous injection of recombinant human bone morphogenetic protein-2 accelerates fracture repair. $J$ Bone Joint Surg Am, 85-A:1425-35.

Einhorn TA. 1995. Enhancement of fracture-healing. J Bone Joint Surg Am, 77:940-56.

Einhorn TA. 1998 The cell and molecular biology of fracture healing. Clin Orthop Relat Res, 355(Suppl):S7-21.

Finkemeier CG. 2002. Bone-grafting and bone-graft substitutes. J Bone Joint Surg Am, 84-A:454-64.

Garrison KR, et al. 2007. Clinical effectiveness and cost-effectiveness of bone morphogenetic proteins in the non-healing of fractures and spinal fusion: a systematic review. Health Technol Assess, 11:1-150, iii-iv.

Gautschi OP, et al. 2007. Bone morphogenetic proteins in clinical applications. ANZ J Surg, 77:626-31.

Govender S, et al. 2002. Recombinant human bone morphogenetic protein-2 for treatment of open tibial fractures: a prospective, controlled, randomized study of four hundred and fifty patients. J Bone Joint Surg Am, 84-A:2123-34.

Groeneveld EH, Burger EH. 2000. Bone morphogenetic proteins in human bone regeneration. Eur J Endocrinol, 142:9-21.

Guo W, et al. 1999. Expression of bone morphogenetic proteins and receptors in sarcomas. Clin Orthop Relat Res, 365:175-83.

Heckman JD, Sarasohn-Kahn J. 1997. The economics of treating tibia fractures. The cost of delayed unions. Bull Hosp Jt Dis, $56: 63-72$

Hollinger J, Wong ME. 1996. The integrated processes of hard tissue regeneration with special emphasis on fracture healing. Oral Surg Oral Med Oral Pathol Oral Radiol Endod, 82:594-606.

Hollinger JO, et al. 2008. Recombinant human platelet-derived growth factor: biology and clinical applications. J Bone Joint Surg Am, 90:48-54. 
Hughes FJ, et al. 1995. The effects of bone morphogenetic protein-2, -4, and -6 on differentiation of rat osteoblast cells in vitro. Endocrinology, $136: 2671-7$

Jones AL, et al. 2004a. Prospective, randomized comparison of rhBMP-2/ ACS in combination with allograft versus autogenous bone graft in healing diaphyseal tibial fractures with traumatic bone loss. Annual Meeting of the Orthopedic Trauma Association. Hollywood, FL, USA.

Jones, AL, et al. 2004b. Use of rhBMP-2 in the treatment of open tibial shaft fractures: do improved clinical outcomes outweigh the additional expense of rhBMP-2? Annual Meeting of the Orthopedic Trauma Association. Hollywood, FL.

Jones AL, et al. 2006. Recombinant human BMP-2 and allograft compared with autogenous bone graft for reconstruction of diaphyseal tibial fractures with cortical defects. A randomized, controlled trial. $J$ Bone Joint Surg Am, 88:1431-41.

Kanatani M, et al. 1995. Stimulatory effect of bone morphogenetic protein-2 on osteoclast-like cell formation and bone-resorbing activity. $J$ Bone Miner Res, 10:1681-90.

Karladani A, et al. 2000. Displaced tibial shaft fractures: a prospective randomized study of closed intramedullary nailing versus cast treatment in 53 patients. Acta Orthop Scand, 71:160-7.

Katagiri T, et al. 1994. Bone morphogenetic protein-2 converts the differentiation pathway of $\mathrm{C} 2 \mathrm{C} 12$ myoblasts into the osteoblast lineage. $J$ Cell Biol, 127:1755-66.

Kawaguchi $\mathrm{H}$, et al. 2001. Acceleration of fracture healing in nonhuman primates by fibroblast growth factor-2. J Clin Endocrinol Metab, 86:875-80.

Khan SN, et al. 2005. The biology of bone grafting. J Am Acad Orthop Surg, 13:77-86.

Kleeff J, et al. 1999. Bone morphogenetic protein 2 exerts diverse effects on cell growth in vitro and is expressed in human pancreatic cancer in vivo. Gastroenterology, 116:1202-16.

Kolbeck S, et al. 2003. Homologous growth hormone accelerates bone healing - a biomechanical and histological study. Bone, 33:628-37.

Kumagai T, et al. 2006. Bone morphogenetic protein-2 suppresses invasiveness of TSU-Pr1 cells with the inhibition of MMP-9 secretion. Anticancer Res, 26:293-8.

Langenfeld EM, et al. 2003. The mature bone morphogenetic protein-2 is aberrantly expressed in non-small cell lung carcinomas and stimulates tumor growth of A549 cells. Carcinogenesis, 24:1445-54.

Lee FY, et al. 2002, Repair of bone allograft fracture using bone morphogenetic protein-2. Clin Orthop Relat Res, 397:119-26.

Li RH, et al. 2003. rhBMP-2 injected in a calcium phosphate paste (alphaBSM) accelerates healing in the rabbit ulnar osteotomy model. J Orthop Res, 21:997-1004.

Lieberman JR, et al. 1999. The effect of regional gene therapy with bone morphogenetic protein-2-producing bone-marrow cells on the repair of segmental femoral defects in rats. J Bone Joint Surg Am, 81:905-17.

Linkhart TA, et al. 1996. Growth factors for bone growth and repair: IGF, TGF beta and BMP. Bone, 19(Suppl 1):1S-12S.

Luppen CA, et al. 2002. Recombinant human bone morphogenetic protein-2 enhances osteotomy healing in glucocorticoid-treated rabbits. $J$ Bone Miner Res, 17:301-10.

Marsh D. 1998. Concepts of fracture union, delayed union, and nonunion. Clin Orthop Relat Res, 355(Suppl):S22-30.

Mayer H, et al. 1996. Subtle differences in the mitogenic effects of recombinant human bone morphogenetic proteins -2 to -7 on DNA synthesis on primary bone-forming cells and identification of BMP-2/4 receptor. Calcif Tissue Int, 58:249-55.

McKay WF, et al. 2007. A comprehensive clinical review of recombinant human bone morphogenetic protein-2 (INFUSE((R)) Bone Graft). Int Orthop, 31:729-34.

Onishi T, et al. 1998. Distinct and overlapping patterns of localization of bone morphogenetic protein (BMP) family members and a BMP type II receptor during fracture healing in rats. Bone, 22:605-12.

Orui $\mathrm{H}$, et al. 2000. Effects of bone morphogenetic protein-2 on human tumor cell growth and differentiation: a preliminary report. $J$ Orthop Sci, 5:600-4.
Ozkaynak E, et al. 1992. Osteogenic protein-2. A new member of the transforming growth factor-beta superfamily expressed early in embryogenesis. J Biol Chem, 267:25220-7.

Pluhar GE, et al. 2001. The effect of recombinant human bone morphogenetic protein-2 on femoral reconstruction with an intercalary allograft in a dog model. J Orthop Res, 19:308-17.

Reddi AH. 1994. Bone and cartilage differentiation. Curr Opin Genet Dev, 4:737-44

Sakou T. 1998. Bone morphogenetic proteins: from basic studies to clinical approaches. Bone, 22:591-603.

Schmitt JM, et al. 1999. Bone morphogenetic proteins: an update on basic biology and clinical relevance. $J$ Orthop Res, 17:269-78.

Seeherman H, et al. 2006a. rhBMP-2/calcium phosphate matrix accelerates osteotomy-site healing in a nonhuman primate model at multiple treatment times and concentrations. J Bone Joint Surg Am, 88:144-60.

Seeherman H. 2001. The influence of delivery vehicles and their properties on the repair of segmental defects and fractures with osteogenic factors. $J$ Bone Joint Surg Am, 83-A(Suppl 1 Pt 2):S79-81.

Seeherman HJ, et al. 2006b. rhBMP-2 delivered in a calcium phosphate cement accelerates bridging of critical-sized defects in rabbit radii. $J$ Bone Joint Surg Am, 88:1553-65.

Soda H, et al. 1998. Antiproliferative effects of recombinant human bone morphogenetic protein-2 on human tumor colony-forming units. Anticancer Drugs, 9:327-31.

Swiontkowski MF, et al. 2006. Recombinant human bone morphogenetic protein-2 in open tibial fractures. A subgroup analysis of data combined from two prospective randomized studies. J Bone Joint Surg Am, 88:1258-65.

Templeman DC, et al. 1998. Update on the management of open fractures of the tibial shaft. Clin Orthop Relat Res, 350:18-25.

Termaat MF, et al. 2005. Bone morphogenetic proteins. Development and clinical efficacy in the treatment of fractures and bone defects. $J$ Bone Joint Surg Am, 87:1367-78.

Tornetta P 3rd, et al. 1994. Treatment of grade-IIIb open tibial fractures. A prospective randomised comparison of external fixation and nonreamed locked nailing. $J$ Bone Joint Surg Br, 76:13-9.

Tsuji K, et al. 2006. BMP2 activity, although dispensable for bone formation, is required for the initiation of fracture healing. Nat Genet, 38:1424-9.

Urist MR. 1965. Bone: formation by autoinduction. Science, 150(698):893-9.

Valentin-Opran A, et al. 2002. Clinical evaluation of recombinant human bone morphogenetic protein-2. Clin Orthop Relat Res, 395:110-20.

Wang EA, et al. 1993. Bone morphogenetic protein-2 causes commitment and differentiation in C3H10T1/2 and 3T3 cells. Growth Factors, 9:57-71.

Watson JT, et al. 1995. Management strategies for bone loss in tibial shaft fractures. Clin Orthop Relat Res, 315:138-52.

Welch R. et al. 1998. Effect of recombinant human bone morphogenetic protein-2 on fracture healing in a goat tibial fracture model. $J$ Bone Miner Res, 13:1483-90.

Whittle AP, et al. 1992. Treatment of open fractures of the tibial shaft with the use of interlocking nailing without reaming. J Bone Joint Surg Am, 74:1162-71.

Whittle AP, Wester W, Russell TA. 1995. Fatigue failure in small diameter tibial nails. Clin Orthop Relat Res, 315:119-28.

Wozney JM, Rosen V. 1998. Bone morphogenetic protein and bone morphogenetic protein gene family in bone formation and repair. Clin Orthop Relat Res, 346:26-37.

Wrana JL, et al. 1994. Mechanism of activation of the TGF-beta receptor. Nature, 370(6488):341-7.

Yamaguchi A, et al. 1991. Recombinant human bone morphogenetic protein-2 stimulates osteoblastic maturation and inhibits myogenic differentiation in vitro. $J$ Cell Biol, 113:681-7.

Young BT, Rayan GM. 2000. Outcome following nonoperative treatment of displaced distal radius fractures in low-demand patients older than 60 years. J Hand Surg [Am], 25:19-28.

Zabka AG, et al. 2001. Histomorphometric description of allograft bone remodeling and union in a canine segmental femoral defect model: a comparison of rhBMP-2, cancellous bone graft, and absorbable collagen sponge. J Orthop Res, 19:318-27. 